\title{
Comunicação e Silêncio na Experiência Política Espinosana
}

[Communication and Silence in the Spinozist Political Experience]

\section{Daniel Santos da Silva ${ }^{\circledast}$}

\begin{abstract}
Resumo: Um problema fundamental ético e político, a comunicação encerra menos a preocupação com a verdade como mero objeto do que com os afetos como exercício de vida e explicitação prática da experiência que ensina. Aqui, alguns elementos são elencados para caracterizar a difícil relação do filósofo - da filosofia, da reflexão, do pensamento crítico - com a violência (anti)política que se expressa, em muitas ocasiões, no verbo "idiota" - porém, às vezes, efetivo - e na proliferação do ódio, do medo e da exclusão.
\end{abstract}

Palavras-chave: Comunicação, silêncio, afetos, política

\begin{abstract}
A fundamental ethical and political problem, communication has less concern with truth as a mere object than with affections as the exercise of life and the practical explanation of the experience that teaches. Here, some elements are listed to characterize the philosopher's - philosophy, reflection, critical thinking - difficult relationship with the (anti)political violence that is often expressed in the verb "idiot" - but sometimes effective - and in the proliferation of hatred, fear, and exclusion.
\end{abstract}

Keywords: Communication, silence, affections, politics

A cautela era, reconhecidamente, a marca de Espinosa. A palavra caute figurava no anel de sinete com o qual selava suas correspondências ao se comunicar com amigos, em muitas das quais eram ressaltados alguns dos perigos que atingem a quem pensa livremente; por outro lado, também outras tantas cartas e escritos de Espinosa nos permitem tomar essa filosofia por uma exposição clara de como a paixão do medo desfigura nossas potências, amortece as veias de comunicação essenciais à própria existência da vida coletiva. Ora, como distinguir a prudência presente no emblema Caute para a comunicação do pensamento livre, sem a confundir com a paixão de medo que a desfigura? Afinal, segundo Espinosa, uma é a potência de viver e resistir pela esperança de vida; outra é a

\footnotetext{
${ }^{*}$ Professor da Universidade Estadual do Paraná (UNESPAR). Doutor em Filosofia pela Universidade de São Paulo. E-mail: danidani_ss@yahoo.com.br. ORCID: https://orcid.org/0000-0002-3841-2516.
} 
potência (ou impotência) na configuração de meios e fins para apenas existir com o medo da morte:

a multidão livre conduzse mais pela esperança que pelo medo, ao passo que uma multidão subjugada conduz-se mais pelo medo que pela esperança: aquela procura cultivar a vida, esta procura somente que evitar a morte; aquela, sublinho, procura viver para si, esta é obrigada a ser do vencedor, e daí dizermos esta é serva e aquela é livre. (...) $\mathrm{E}$ embora entre o estado que é criado pela multidão livre e aquele que é adquirido por direito de guerra, se atendermos genericamente ao direito de cada um, não haja nenhuma diferença essencial, contudo, quer o fim, como já mostramos, quer os meios com os quais cada um deles se deve conservar têm enormes diferenças (ESPINOSA, 2009, p. 45)

Porém, ainda que o medo indique servidão, ele é paixão insolúvel e encarnada em muitos dos movimentos afetivos que realizamos entre outras pessoas, muitas vezes a serviço de barrar a ambição de quem se imagina melhor e vive como melhor frente à potência da multidão. De qualquer maneira, ao propormos a questão sobre comunicação e o silêncio na política, raramente a prudência, a deliberação ou a cautela foram reduzidas na filosofia à paixão do medo. Há linhas que podem ser bem demarcadas entre as duas posturas: na cautela, um certo conhecimento das coisas do mundo tende a orientar os passos a serem dados se temos em vista um fim; o medo, em geral, apenas desnuda nossa impotência e ignorância, por isso não nos surpreende que, inclusive, quem se guia por tal paixão se ponha a vociferar e a fingir destemor quando instâncias determinadas garantem proteção ou anonimato. O medo pode fazer calar, mas pode igualmente fazer gritar alucinadamente. A cautela, por sua vez, também pode nos fazer calar, mas nunca completamente como mostraremos a seguir, e o grito que pode acompanhar a cautela é de outra natureza que a do medo - uma espécie de conhecimento que acompanha a cautela faz do grito algo expressivo de quem se comunica; a cautela esconde o que pode ser escondido (não há desejo de martírio), mas expõe o que pode e deve ser vivido.

São sentidos de urgência dis- 
tintos, mesmo assim não dicotômicos, pois somos habitados por afetos múltiplos e a coerência que deles podemos trazer conosco é sempre esforço (conatus). A prática espinosana da filosofia funda-se no desejo (conatus-cupiditas) também de comunicar-se, e a coerência de nossos esforços está mais na necessidade de fazer fluir experiências vitais do que em produzir discursos sem contradições. Nesse sentido, o mais determinante são os afetos comuns, que nos assemelham e nos diferenciam em nossas experiências vitais e se expressam a nossas próprias vistas. A experiência de comunicar-se, então, é por demais complexa e não reside apenas em disseminar ideias adequadas (em uma sorte de vanguardismo filosófico), tampouco em simplesmente informar (um certo tipo de razão instrumental discursiva). Em vez disso, o ponto comum de que partimos para compreender as experiências políticas são as paixões, os afetos comuns, como medo e esperança tal como se apresentam na prática, aqui retomada para relembrar o lema espinosano do Tratado político: a reivindicação por uma filosofia política que compreenda as paixões de modo realista e não utópico, e que portanto não seja apenas saber teórico discursivo distante da prática. Sem serem condenadas pela imagem de uma natureza de- caída e víciosa, as paixões serão ali compreendidas como propriedades humanas, tal com o plano e a reta são propriedades das figuras geométricas. As paixões entretecem as relações dos seres humanos como prevalentemente ambiciosos, invejosos e ávidos de distinção, ao mesmo tempo em que pelas mesmas propriedades da natureza humana compreendemos também a solidariedade, a generosidade, a fortaleza.

Os afetos mais ativos que decorrem de nossa natureza são, concretamente, exercício vivo de relações que carregam consigo o pensamento reflexivo; são igualmente produções efetivas de laços entre o indivíduo e o que o cerca, mais firmes que a parceria efêmera com as coisas e pessoas fundada na riqueza, no prazer ou na glória, ou em outras paixões dessa estirpe, para lembrar o proêmio Tratado da emenda do intelecto (Espinosa, 2015b). Ao fim, não é a "ideia da verdade" que determina nossas ações, pois mesmo no campo da compreensão racional, a potência intelectual que somos é tomada como expressão de afetos. A verdade portanto não opera como negação das paixões e nem uma ideia verdadeira é capaz de refrear as paixões, afinal, é a força de um afeto contrário e mais forte (seja ele racional ou irracional, adequado ou inadequado) que pode 
suprimir, por exemplo, o medo ${ }^{1}$. Esse contexto nos aproxima de ideias fundamentais da ética espinosana e poderá nos oferecer o real sentido afetivo do que o filósofo entende por cautela.

Certo dia, encontrei um texto de Joaquim de Carvalho sobre o anonimato de Espinosa na publicação do Tratado Teológico-político que traduz o que aqui defendemos a propósito de sua cautela: o anonimato do Tratado Teológico-Político não é prova de repulsiva cobardia; pelo que sabemos, ou antes ignoramos, da índole de Espinosa, pensamos antes que é testemunho da humanitas seu modestia, virtude que a Ética admiravelmente define (CARVALHO, 2019).
Espinosa não nascera com alma de mártir. Ele tinha que dizer aos contemporâneos e aos vindouros; preocupava-o o destino da mensagem, e não a fama de a haver proferido. Se declarasse o nome, abriam-se-lhe as portas do cárcere, e à infâmia da pessoa sucederiam a reclusão e a ignorância do seu pensamento. Onde está o filósofo que não anteponha a discussão das ideias ao renome da pessoa, ao viver o perviver, e para resguardar o destino das suas meditações não recate o ser físico, se isso for propício? Não;
O anonimato recobre a prudência e, não menos, a urgência de intervir filosoficamente na experiência comum política que, por sua vez, intervinha diretamente em sua vida, a ponto de quase ser morto quando esfaqueado por um "inimigo" amedrontado pelo livre pensar. No caso, a pobre experiência política do medo das livres ideias não se identifica prontamente às atitudes violentas de quem teme o livre comunicar-se - ao contrário, podemos afirmar que a violência é a fronteira para lá da qual a experiência política "torna a ser" experiência de guerra (não de conflito, nos moldes a que estamos acostumados contemporaneamente, pois aqui retomamos a partir de Maquiavel e Espinosa a reflexão sobre direito de guerra).

\footnotetext{
${ }^{1}$ Remeto à quarta parte da Ética, Proposição I (Espinosa, 2015a, p. 383): “Nada que uma ideia falsa tem de positivo é suprimido pela presença do verdadeiro, enquanto verdadeiro"; e a Proposição VII (Espinosa, $2015 a$, p. 389): "Um afeto não pode ser coibido nem suprimido a não ser por um afeto contrário e mais forte que o afeto a ser coibido."
} 
Espinosa seguia as trilhas de um mundo político, em seu tempo, que insinuava constantemente o terror como força capaz de manter unida a república, de fazer passar a disseminação da violência por força integradora e restauradora de potência política.

Assim, a cautela provoca silêncios estratégicos e pode ocultar um nome enquanto expõe algo profundamente político, e deve saber discernir, na experiência política, o que esta experiência revela de violento, de antipolítico, de desejo de exclusão e destruição. A maior dificuldade surge exatamente quando a comunicação ela mesma e suas condições de efetividade são deturpadas até que a violência que perpassa certas ações seja vista como ato político - como as que se substanciam na negação da alteridade, das diferenças -, e que as possibilidades de comunhão sejam tão bloqueadas às nossas vistas cansadas do cotidiano que o que diz respeito, de fato, à cidade, passa a ser negligenciado ou mesmo excomungado como pérfido e prejudicial podemos reconhecer bem a persis- tência, nesse caso, da imagem do político' 2: pérfido, sempre a preparar armadilhas, e sua extrapolação justamente segue na mesma esteira daquilo que poderia produzir o reverso, alguma forma de esclarecimento na multiplicação dos meios de comunicação.

O falar e o calar, sentimos muitas vezes, constituem uma experiência ética tanto quanto política. Espinosa escreve no escólio da segunda proposição da terceira parte da Ética: "as coisas humanas dar-se-iam muito mais felizmente se nos homens estivesse igualmente o poder (potestate) tanto de falar quanto de calar. Ora, a experiência ensina mais que suficientemente que os homens nada têm menos em seu poder do que a língua, e que nada podem menos do que moderar seus apetites" (Espinosa, 2015, p. 245). Se a política existe em função da dificuldade intrínseca à existência humana de moderar os apetites, existe, também, como esfera de moderação da fala - e o moderar também nos envia ao governar, ao criar medidas (impor a justeza). Nesse sentido, o campo político põe-se também

\footnotetext{
2 Cf. Tratado Político (ESPINOSA, 2009, pp. 6-7): “Os políticos, pelo contrário, crê-se que em vez de cuidarem dos interesses dos homens lhes armam ciladas e, mais do que sábios, são considerados habilidosos. A experiência, na verdade, ensinou-lhes que, enquanto houver homens, haverá vícios. Daí que, ao procurarem precaver-se da malícia humana, por meio daquelas artes que uma experiência de longa data ensina e que os homens, conduzidos mais pelo medo que pela razão, costumam usar, pareçam adversários da religião, principalmente dos teólogos, os quais creem que os poderes soberanos devem tratar dos assuntos públicos segundo as mesmas regras da piedade que tem um homem particular. É no entanto inquestionável que os políticos escreveram sobre as coisas políticas de maneira muito mais feliz que os filósofos. Dado, com efeito, que tiveram a experiência por mestra, não ensinaram nada que se afastasse da prática."
} 
como produtor de sentido de falas e pode ser encarado como condição de muitas expressões comuns, mas, inversamente, pode ser terreno de violência àquilo que se constitui comunitariamente.

A violência pode estar no calar, aquela a que mais atentamos, normalmente; pode estar também, contudo, no fazer falar, no induzir à expressão falada, forma menos costumeira, aparentemente, mas das mais recorrentes em nossos dias. O transtorno dessa forma de indução à tagarelice é legível na escrita de Espinosa, seja porque admite que, apesar de não ser tão fácil submeter ânimos como se submetem línguas, os ânimos estão de certa forma sob os poderes soberanos e se submetem aos meios capazes de levar a maioria a amar e odiar o que querem tais poderes - mais, a gritar de ódio ou de amor com a medida, a "moderação" requerida para suas finalidades (ESPINOSA, 2008, p. 252); seja, enfim, porque prognostica, nessa menor dificuldade em dominar as línguas que os ânimos, a necessária violência em que recai toda forma de poder que se exerce sobre nossa liberdade de raciocinar e de ajuizar. Em relação a isso, lembremos as primeiras linhas do último capítulo do Tratado Teológico-Político:

\section{Se fosse tão fácil mandar}

nos ânimos como é mandar na línguas, não haveria nenhum governo que não estivesse em segurança ou que recorresse à violência, uma vez que todos os súditos viveriam de acordo com o desígnio dos governantes e só em função das suas prescrições é que ajuizariam do que era bom ou mau, verdadeiro ou falso, justo e iníquo. (ESPINOSA, 2008, p. 300)

O tom quase matemático não surpreende, pelo menos a quem não espera juízo moral dessa filosofia política: o que temos, no contexto dessa citação, é uma sorte de alerta a quem pretende dominar e como isso apenas é possível se a potência de muitos dá suporte a tamanha ambição, a consequência mais necessária que daí segue é a violência, sempre à sombra de pensamentos e práticas irredutíveis em sua persistência éticopolítica. A liberdade de fala, estudo e ensino diferencia-se do cultivo da fala violentamente antipolítica como a resistência de quem deseja a liberdade diferencia-se do desejo de abandonar a potência própria. Nessa configuração em que a fala antipolitica exerce o domínio político, são os indivíduos mais notáveis pelo conhecimento e pelo exercício da comunicação, 
pelo envolvimento livre e afetivo com as partes mais violentadas da cidade que serão os primeiros perseguidos nos confrontos - ainda que verbais - que se instalam em meio à "comunidade" 3 ,

O "mandar nos ânimos e nas línguas" em nome da segurança a que busca o exercício violento de poder, no Tratado Teológicopolítico, não se identifica, pois, com a definição de segurança do Tratado político 4 , entendida como uma virtude da cidade correspondente à virtude privada que, justamente, preserva a liberdade e a fortaleza do ânimo. Neste caso, a individual liberdade de ânimo (ou fortaleza) se realiza na mesma medida em que sinaliza a concreção dos direitos naturais dos indivíduos em atividade comum, como vemos muito bem articulado no segundo Tratado. Paralelamente, a ilusória "liberdade" de expressar em fala o ódio - ou de perseguir odiosamente a fala livre -, nessa configuração em que complexos imaginários (efetivos) de dominação formatam a política, é impregnada de arrebatamento em crenças e em desprezos que surgem, como escreve Espinosa, sob a autoridade e a orientação de quem domina - "o que a experiência abundantemente confirma" (ESPINOSA, 2008, p.252).

E porque são muitos os indivíduos orientados pela liberdade ilusória e arrebanhados pela ambição de domínio de poucos, ou a imagem da política se aproxima da dinâmica de um sindicato de ladrões, ou ela é reformulada. Ora, isso que implica outra armadura para o que se considera a experiência política, outra medida (moderação) para o que se tem vulgarmente por ação política e, na mesma corrente, por ação pública. Se o pouco poder que temos sobre nossas línguas pode ser deixado a quem deseja dominar; se, além disso, para dominar é preciso atacar os ânimos dos indivíduos, um meio eficaz para isso seria exatamente, em primeiro lugar, dar à voz submissa

\footnotetext{
${ }^{3}$ No Tratado Teológico-político (ESPINOSA, 2008, p. 307): “Quanto mais não valeria conter a ira e o furor do vulgo, em vez de promulgar leis inúteis que só podem ser violadas por aqueles que prezam as virtudes e as artes, leis que reduzem o Estado a uma situação tal que é incapaz de defender os homens livres! Que coisa pior pode imaginar-se para um Estado que serem mandados para o exílio como indesejáveis homens honestos, só porque pensam de maneira diferente e não sabem dissimular? (...) os que sabem que são honestos não têm, como os criminosos, medo de morrer nem imploram clemência; na medida em que não os angustia o remorso de nenhum feito vergonhoso recusam-se a considerar castigo o morrer por uma causa justa e têm por uma glória dar a vida pela liberdade. Que exemplo poderá então ter ficado da morte de pessoas assim, cujo ideal é incompreendido pelos fracos e moralmente impotentes, odiado pelos revoltosos e amado pelos homens de bem? Ninguém, certamente, aí colhe exemplo algum, a não ser para os imitar ou, pelo menos, admirar."

${ }^{4}$ No Tratado Político (ESPINOSA, 2009, p. 9): "Nem importa, para a segurança do estado (imperium), com que ânimo os homens são induzidos a administrar corretamente as coisas, contanto que as coisas sejam corretamente administradas. A liberdade de ânimo, ou fortaleza, é com efeito uma virtude privada, ao passo que a segurança é a virtude do estado".
} 
todo incentivo à fala (entendida aqui como falsa liberdade de comunicação), e, em segundo lugar, inversamente, à verdadeira liberdade de juízo e de ânimo dar ares de subversão, de amotinamento, $o$ qual é fundado, em realidade, na comunicação do que é verdadeiramente útil ao comum.

Nessa configuração, em ambos os casos, o medo é o afeto mais comum, ainda assim traços diversos denunciam a natural diferença entre os locais em que habita; se pensamos em termos maquiavelianos, notamos que o desejo de domínio é inseparável do medo a tudo, medo da verdade - como desejo de ser enganado ${ }^{5}$-, eis uma das razões de não poder durar, e Espinosa relembra Sêneca para afirmar que o despotismo tem necessariamente vida curta (Espinosa, 2008 , p. 86). Por outro lado, o desejo de não ser dominado - e também o desejo que persiste em não ser governado por semelhantes enlaça o medo inevitável pela própria sobrevivência, mas especial- mente questiona a permanência da vida como simples sobrevida ${ }^{6}$.

Talvez, então, possamos perspectivar como resistência a negação a aderir à fala orientada, e quem sabe até possamos ver nisso o silêncio como constituição, em alguns momentos, de verdadeira aliança comunicativa. Em certas configurações, há resistência ativa no silêncio, assim como há igualmente cautela no pronunciar-se ou no anunciar-se; inevitavelmente, existe o vazio das falas submissas e fundadas na negação e no medo da liberdade comum. Para que uma asserção como essa faça sentido, hoje, não liguemos à ideia de dominação apenas governantes políticos, já que meios e instrumentos de subjugação do ânimo muito se complexificaram e refinaram-se. A eficácia atual sobre os ânimos já é capaz de fazer parecer bobagem falar - criticamente, não como frase pronta de mercadoria - em desejo de liberdade.

Portanto, a violência política

\footnotetext{
${ }^{5}$ Cf. essa bela passagem de MARILENA CHAUI, em Política em Espinosa, p. 279: “O soberbo, no orgulho desmedido, considera que tudo lhe é permitido; o abjeto, na humilhação desmedida, considera que nada lhe é permitido. O primeiro se torna dominador insolente; o outro, servo adulador, invejoso e ressentido. Ambos, submissos às suas paixões, são fonte de novas servidões, pois o soberbo julga-se livre porque domina e despreza os outros, enquanto o abjeto adulador imagina-se dependente dos favores do soberbo que, por definição, nunca hão de vir. Assim, o segundo movimento do texto do Político (VII, 27) inicia-se quando, transferido o topos liviano da plebe para o vulgar, passamos daquele que se deixa enganar por inexperiência e ignorância àquele que deseja ser enganado por orgulho e ambição ou por auto-abjeção. Por isso, servidão e liberdade não andam juntas, pois o soberbo é servo de suas paixões que o fazem servo de seus aduladores e estes, servos de suas paixões que os fazem servos do dominador."

${ }^{6}$ Cf. Tratado Político (ESPINOSA, 2009. p. 45): “Quando, por conseguinte, dizemos que o melhor estado é aquele onde os homens passam a vida em concórdia, entendo a vida humana, a qual não se define só pela circulação do sangue e outras coisas que são comuns a todos os animais, mas se define acima de tudo pela razão, verdadeira virtude e vida da mente."
} 
não existe porque há ânimos insubmissos - simplesmente existem potências singulares e atividades comuns, e a violência acompanha o desejo de dominar, o qual em geral tem braços curtos e voz rouca, pois, para homenagear La Boétie, precisa invariavelmente de muitos braços e vozes estridentes para agir, e a arena política é um palco bem iluminado para isso. É nessa linha que, do ódio, do desprezo e de tudo mais surgido do desejo de dominar de poucos, Espinosa afirma:

$E$, se bem que esses sentimentos não surjam diretamente por ordem do soberano, muitas vezes, como a experiência abundantemente confirma, eles surgem, no entanto, por força de sua autoridade e sob sua orientação... daí que possamos conceber, sem violentar minimamente a inteligência, homens que não acreditem, odeiem, desprezem ou sejam arrebatados por qualquer outro sentimento a não ser em virtude do direito do Estado (ESPINOSA, 2008, p.252).
Suponho, pois, que a cautela e a potência que ela envolve mais que nunca passam por resistir a certas falas, a calar o nome de si em ocasiões determinadas, a comunicar até no silêncio, mas repudia maximamente o medo, mesmo que dele não se livre completamente, muitas vezes. Por outro lado, suponho que a comunicação constitutiva da experiência política, múltipla, obviamente, é hostil à proliferação do ódio e da exclusão, e que toda resistência ou ação livre, quando política, é conflito direto com quem usurpa o direito do indivíduo dando-lhe voz - que, quando útil, é conquistada, não dada - e orientando de mil modos sua fala, que assim será constantemente uma fala contra, generalizante; nem por isso todas e todos que assim falam aderem de fato ao ódio, ao desprezo, é de se notar que violências são exercidas sobre individuos quando na cidade os instrumentos mais eficazes de comunicação são antipolíticos, e a política passa a alimentar a ilusão de que a voz publicizada é já voz política, ocultando que a experiência que aí se constitui é primordialmente de negação, de subserviência - de circo, por que não? 


\section{Referências}

CARVALHO, J. de. "Espinosa e a publicação do Tratado teológico-político". Artigo eletrônico. [Acessado em 03 de junho de 2019]

CHAUI, M. Politica em Espinosa. São Paulo: Companhia das Letras, 2003.

ESPINOSA, B. de. Tratado político. Trad. de Diogo Pires Aurélio. São Paulo: Martins Fontes, 2009.

Ética. Trad. do Grupo de Estudos Espinosanos. São Paulo: Edusp, 2015a.

. Tratado teológico-político. Trad. Diogo Pires Aurélio. São Paulo: Martins Fontes, 2008.

. Tratado da emenda do intelecto. Trad. de Cristiano Novaes de Rezende. Campinas: Editora da Unicamp, 2015b.

LA BOÉTIE, Etienne. Discurso da servidão voluntária. Trad. Laymert Garcia dos Santos. São Paulo : Brasiliense, 1999.

Recebido: 04/07/2019

Aprovado: 09/11/2019

Publicado: 17/11/2019 